\title{
Analysis of meteoritic activity in the Vth-XVth centuries using an extended survey of European Medieval Sources.
}

\author{
María José MARTÍNEZ ${ }^{*}$, Francisco J. MARCO \\ ${ }^{1}$ Universidad Politécnica de Valencia. Dept. Matemàtica Aplicada. IUMPA. Camino de \\ Vera SN. 46022. Valencia. Spain. \\ ${ }^{2}$ Universitat Jaume I. Dep. Matemàtiques. IMAC. Campus de Riu Sec. 12071 Castellón. \\ Spain \\ *Corresponding Author: mjmartin@mat.upv.es
}

\begin{abstract}
:
Meteor streams are formed of meteoroids left behind mainly by comets. A meteor shower happens while the Earth crosses a stream. Meteoritic can be classified into either sporadic meteors or shower meteors. We consider the new compilation of meteor records in the diverse European Medieval sources and investigate the distribution of meteor streams along the year from the $5^{\text {th }}$ century to the $15^{\text {th }}$ century. We have also considered the records of meteor showers and storms in the chronicles of Korea, Japan, China and Arab, and compare their appearance dates with those of showers obtained above, as well as with the modern observations. We confirm that the three sets of data are in agreement with each other. Being the most representative meteor showers Perseids, Leonids, and Lyrids.
\end{abstract}

Keywords: History and Philosophy of Astronomy, meteors, meteoroids.

\section{Introduction}

Meteoroids, meteor showers and, in particular, meteor outbursts are one of the most outstanding astronomical phenomena visible to the naked eye. Ancient and medieval observers were aware of such astronomical events and soon began to take records of them, being the oldest known account linked to a modern shower the Lyrids outburst seen in China on March 16, 687BC (Julian calendar). They were considered mainly as omens or signals from heaven for a long time. In fact, it was not until the last half of the XVth century when scientific questions about meteors began to be answered. But still, systematic study of meteors had to wait until the famous Leonids outburst on November 13, 1833. Since then, the progress has been continuous and currently, meteor showers are considered as the results of the stream of debris of comets approaching from one direction and colliding with the Earth's atmosphere. A working list of Meteor showers is maintained at the IAU's meteor data center (Jopek \& Kanuchova, 2016) with 701 proposed showers, 112 of them established.

Ancient records of meteoritic activity are found worldwide but they come mainly from Asia, focusing the attention of researchers from the XIXth century. When we deal with 
Asian data, we refer mainly to three areas of origin of records: China, Japan, and Korea. The most recent study of these data may be found in Yang et al (2005)

The first wide compilation of Chinese accounts was carried out by Biot (1841) and then it has been enlarged and corrected by other authors, especially Imoto \& Hasegawa (1958) and Hasegawa $(1992,1993)$ Some partial studies regarding to specific meteors showers have also been arranged, see for example Fujiiwara \& Hasegawa (2001) . All the meteor observations in the Chinese chronicles are included in the General compilation of Chinese Ancient Astronomical records (Beijin Observatory, 1988). More recently Pankenier, et al (2008) provided new translations for the Chinese text and corrected some errors of dating.

Japan has only a small amount of records of meteors occurrences and they are mainly compiled in three books: Japanese Historical Astronomical Records, General Inventory of Japanese Historical Astronomical records and Japanese Historical Astronomical records since 1600. Imoto \& Hasegawa (1958), Hasegawa (1999) and then Yang, et al (2005) have studied them.

The previously mentioned authors, together with Ahn $(2003,2005)$ researched the Korean area. Korean records come mainly from three official History books: Samguksaki, Goryeosa and Joseonwangjosillok that have been analyzed by Yang et al (2005). These books cover long periods of time and contain astronomical phenomena that were systematically recorded by court astronomers.

As for other parts of the world, Medieval Arabic data have been compiled by Rada \& Stephenson (1992), and then corrected by Kidger (1993), Hasegawa (1996) and Cook (1999), representing a small but significant collection.

Lastly, the compilation of accounts from European sources has been carried out by several authors, such as Chasles, (1841), Quetelet, (1841), Newton, (1864) and more recently focusing on Medieval sources, by Dall'Olmo (1978). Jenniskens (2006) lists a large number or meteor showers based mainly on Asian records and where European records were under-represented, mainly because of the scarce data; the largest survey was provided by Dall'Olmo (1978) but only a few entries can be used for analysis, even including meteor showers and sporadic meteors. This scarcity of data caused strange results as, for example, the fact that Perseids seemed not to have been observed in Europe. The problem arises in European records because, unlike Korean, Chinese and Japanese, no book of ancient astronomical records has been so far compiled. The search of new records is hard because these accounts are found in chronicles, annals and diaries that have no astronomical function and that are not systematically published so, a complete compilation of all such astronomical phenomena remains a hopeless task.

In this paper, we will carry out a study of the meteor showers covering the Vth-XVth centuries. Several authors have already arranged this task but always with a focus on the Asian records, due to the already mentioned small accounts of records from Europe, that we have significantly expanded in a recent paper Martínez \& Marco (2017). Throughout this paper, we briefly study this new European data separately and then we consider 
together with all the available data from other parts of the world, including the new records provided by Yang et al (2005) for the Asian area and Basurah (2012) for the Arabic area. We focus on four main objectives:

1. The verification of whether the current active meteor showers have their counterpart in medieval ages.

2. The study if the current pattern of meteor phenomena has maintained in time.

3. The obtention of some particular results regarding Leonids and Perseids.

4. The comparison with the results provided by other authors.

To this aim, we must refer in the first place to an indispensable and already completed, previous work: the enlargement of the list of European medieval meteor activity reports. A new revision of Dall'Olmo (1978) survey of European showers has been carried out by Martínez \& Marco (2017). In this regard, our plan of work consisted of three parts: first, we proceeded to review the original list of sporadic meteors and meteor showers. Second, we performed a completely new search in all sources used by this author using the new computer resources available to us. Thirdly, we added a large number of new sources, including those from Western Europe that had remained, in this respect, almost unexplored. They are mainly Spanish and Portuguese, as well as some others from Eastern Europe with available English translation. In the next paragraphs, we provide an expanded explanation for each stage.

Regarding the first step, namely the revision of the list given by Dall'Olmo, it should be noted that this author provided a total of 133 observations, 62 of which are completely dated, including year, month and day. For other 17 reports it was possible to determine the year and the month, but not the day. Our first objective was to locate the events in the sources given by Dall'Olmo (1978) and, if necessary, correct any errors or typos. As an example of such corrections, the shower listed on April 4, 1040 actually happened on April 4, 1094. Finally, the study of the context allowed us to provide a complete date to some records, such as the observations of the meteors of 1187 or those in August 1287.

Secondly, we use the computer resources at our disposal to carry out a search as exhaustive as possible in the sources already used by Dall'Olmo, in order to complete his list. In this phase, we strictly limit ourselves to those used by this author: $M G H, R I S$, Rer. Brit. M.A. Script. and some other isolated French, English and Italian chronicles. Then, in a third step, we expanded our study by adding other sources lesser known or never used, from Spain, Portugal and Russia among others, collected both from collections or particular sources and that, sometimes, have not been transcribed into modern writing. In addition, we also included other compilations such as Historia Sagrada, or the Portugalia Monumenta Historica together with many minor documents. Most of them were written in Latin, but we also found them in Castilian, Catalan, Portuguese or Italian. For geographical reasons, we also included the records that refer to meteoritic phenomena seen in Andalusia (southern Spain), in spite of the fact that this area was, in whole or in part, under Arab domination between the V-XVth centuries 
and, therefore, belongs to a different cultural field. Further details will be provided in the next section.

With all the steps above accomplished, we finally offered a list of the observations in which we include the date (the Julian date, but in the case of Arabic observations, we also give the Anno Hegirae or AH), sometimes deduced through the historical context because the original author did not provide any. We included a brief translation of the phenomena and, in some exceptional cases, we could provide details such as the place, the time of the day or the path followed by the meteor. In total, we listed more than 350 observations, most of them dated at least monthly. The main goal of this paper is to include these new records in the analysis of ancient showers, focusing on the V-XVth centuries. In order to obtain higher reliability, through this paper we consider suitable data only those that provide a precise date and, in addition, that can be identified as meteors or meteor showers with security.

As for the rest of the paper, we perform an analysis of the European records for both major showers and sporadic meteors, then we compare the results with those obtained by other authors. We also consider the totality of the worldwide data. Most of the accounts can be identified as belonging to major showers such as Perseids or Leonids, but many have no present-day counterpart.

\section{The European records}

The data on which we are going to work can be classified into two broad categories: star showers and sporadic meteors. A more detailed subclassification, for example, in bolides or meteor outbursts, is generally not possible given the general lack of data in the descriptions. A typical European complete record includes the date, the approximate hour of the observation and seldom some other additional details such as the velocity, color, duration or even the presence of sound. However, most of them are merely variations of a descriptive paragraph such as "stars fell like rain".

In contrast to many Asian and Arabic accounts, medieval European observations regarding meteors were not recorded by professional astronomers. We can generally expect poor accuracy and they do not have a divinatory aim although, sometimes, they are seen as omens that predict an important death, a plague epidemic or foresee the result of a battle. Observations are never systematic and they depend on the perception of the observer, the climate or, simply, the luck. When working with ancient observations of meteors, we must take into account that naked-eye observers can only see those meteors with magnitudes brighter than 5. So that when an observer speaks of the appearance of many shooting stars, the phenomenon probably included many more elements that went unnoticed.

Unlike the cases treated by authors who study the sources from Asia, in Europa we do not have works that narrate the evolution of a dynasty of rulers over hundreds of years, with successive scribes aiming to the same objective. In the European case, as a general 
rule, the primary sources cover short periods of time, and they are usually written by a single author or, in any case, a few of them. On multiple occasions, they are reworkings or copies of older works, because an important characteristic of the European Medieval literate tradition is its cumulative character. The authority of any work was enhanced by grounding in the works of previous writers.

Most scholars have obtained their data from the well-known compilations of works such as the MGH and RIS. Monumenta Germaniae Historica (MGH) is a comprehensive series of primary sources, including chronicles and archives, for the study of mainly German history although many sources from other countries are also included (Britain, Czech lands, Poland, Austria, France, Low Countries, Italy, Spain, etc.). More information can be found in (http:// http://www.mgh.de/, in German). On the other hand, the Rerum Italicarum Scriptores (RIS) is a compilation of texts and literary sources regarding the Italian history from the VIth to the XVth centuries. The initial idea of this work was due to L. A. Muratori in the XVIIth century and the first series was already published in 28 volumes from 1723 to 1751. The work is currently ongoing. We have used the two first series of Muratori (RIS 1723 and RIS ${ }^{2} 1900$ )

As previously stated, the initial investigations in such compilations only provided a reduced amount of data. In Martínez \& Marco (2017) we made a wider research including other less known compilations such as the Portugaliae Monumenta Historica (PMH, 1856) and España Sagrada (1747) together with other local documents such as minor annals, chronicles, and even personal diaries. Annals are simple listing, year by year, of the significant events which have happened in them. The concepts of annals and chronicles are somehow overlapped, but generally, the term annals relates to writing up events as they happen, rather than a long retrospective look into the events of the past, which is more in line with the definition of chronicle. Their origin is grounded in the monastic practice of recording the events of the past year in the spaces and margins of the tables of the date of Eastern.

Many historical words followed a format consisting of providing a brief summary of the events of the world from the first days of creation up to some relatively recent time, followed by a chronicle or annal format of the events of the writer's own time. This genre has a long history. In the early $\mathrm{V}^{\text {th }}$ century a Spanish writer, Paulus Orosius, wrote his Historiae Adversus Paganos that was considered as the first history of the world from a Christian viewpoint, and consequently to its great significance for the missionising monks of the Dark Ages, it was transcribed and translated over the centuries.

Chronicles in any vernacular language were almost unknown before 1200, as the monastic scribes followed the literate tradition of writing in Latin. A special case of such documents is the so-called "dietaris". The Catalan word "Dietari" refers to a historiographical genre that provides news with a higher frequency and volume than 
annals and chronicles. For an explanation of the term, see the Diccionari de la Llengua Catalana (Institut d'estudis Catalans, http://dlc.iec.cat/). In a wider sense, a dietary is simply a document where daily facts are recorded. Most of these recordings are written by particular individuals from the nobility, clergy, but also commoners. Writing is not rigid, nor is it subject to formalities. No phenomenon, familiar or political, is exempt from being collected in a dietari. The events that caught the attention of the writer were conveniently recorded, so they represent a source of astronomical phenomena: eclipses of sun and moon, comets, meteors ...

All the new European data come from the sources that have been mentioned and commented previously and, given the enormity of the existent sources, it is not intended that the list is complete. For a complete exposition of the problems found regarding the translation and the adjudication of a report to a given phenomenon, see Dall'Olmo (1980)

\section{Results}

\subsection{General Overview, including new European data}

The new survey of European data provides an amount of 80 showers and 113 isolated meteors for the considered period. The original list of Dall'Olmo (1978) contained 22 showers and 37 sporadic meteors. If we consider together all the published data: European, Arabian (17 showers, 24 meteors), Chinese, Japanese and Korean (146 showers, 1499 meteors) and eliminate duplicate showers, we have a total amount of 233 meteor showers and 1606 isolated meteors for the period between the Vth and the XVth century. The new European accounts suppose a significant increase of the observations of these centuries and a $34 \%$ of the showers. In figure 1 we display the observations distributed in four periods of about three centuries. Most observations belong to the XIXIV centuries period, and the least observations are in the 400-700 period, as one could expect. At first sight, if we identify the prominent peaks to major meteor showers, Perseids seem to be missed in the 700-1000 period while they are easily identified in the rest of periods. Leonids seem to have been a constant and Lyrids appear in the 700-1000 periods and seem to have experimented an increment in the 1000-1300 period.

A meteor shower is caused by the meteor stream provided by the debris of a comet. If the stream remains in time and position, the meteor shower appears with a radiant at the same constellation each time that the Earth crosses the stream in successive years. The meteors caused by a shower or stream are likely to fall at nearly the same time of year, while sporadic meteors fall randomly. However, any concentration in appearance dates of meteors in can be thought of as a sign of a meteor shower.

The period of an annual shower is one sidereal year. The differences between a sidereal year and tropical and anomalistic year are cumulative so all the observations should be corrected. In this paper, we first locate meteor showers ranging the Vth-XVth centuries and then compare their appearance dates with the modern observations to identify them. 
For meteor showers, astronomers usually rely on the solar ecliptic longitude $(\lambda \odot)$ which is defined by the angle in degrees along the ecliptic from the Vernal equinox to the position of the Earth. This has been also used as the first criterion of identification of a meteor shower when we compare the solar longitude of the date with the list provided by Jenniskens et al (2016).

In figure 2 we see a comparison of the data obtained from European+Arabic sources and Asian sources along the range of time. Biot's data of sporadic meteors (Biot, 1841) have been initially excluded because they create a distorted image. As when we consider only European data, in figure 1, we see that the peak of observations is sited around the XIIth century.
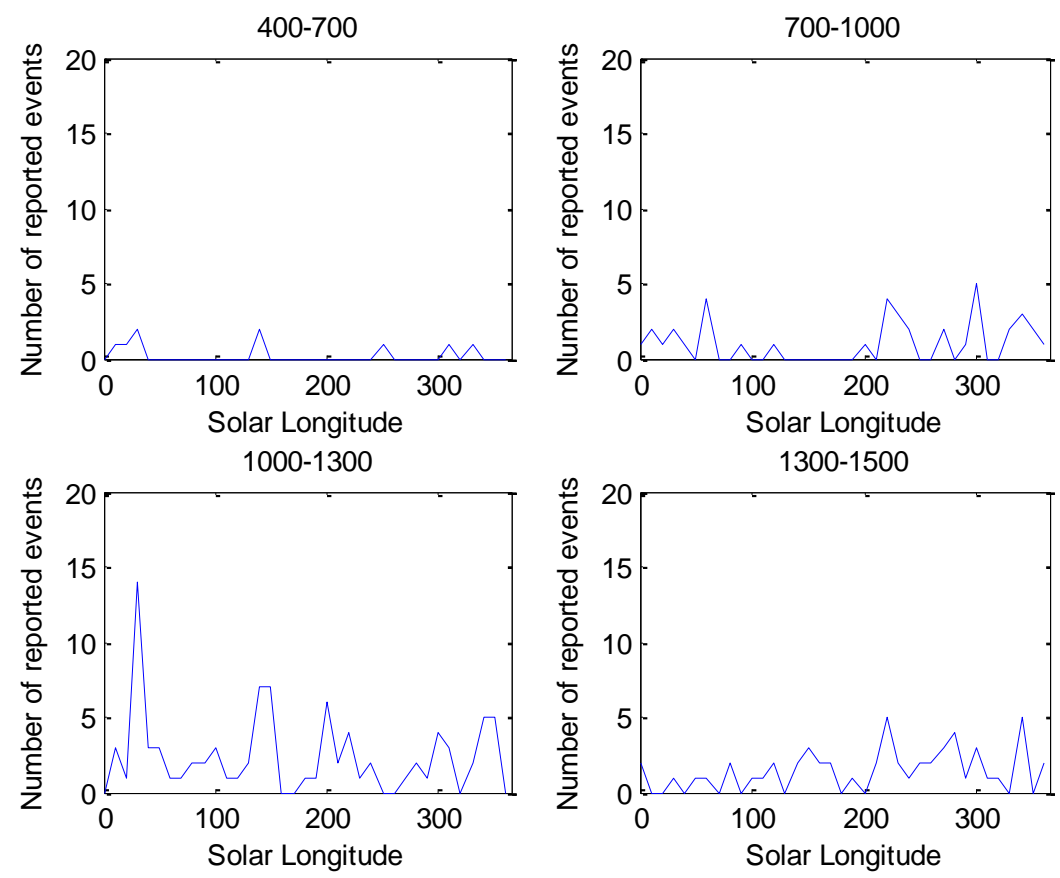

Figure 1: Meteors records in Europe in periods of about 300 years. The data include sporadic meteors as well as meteors showers. 


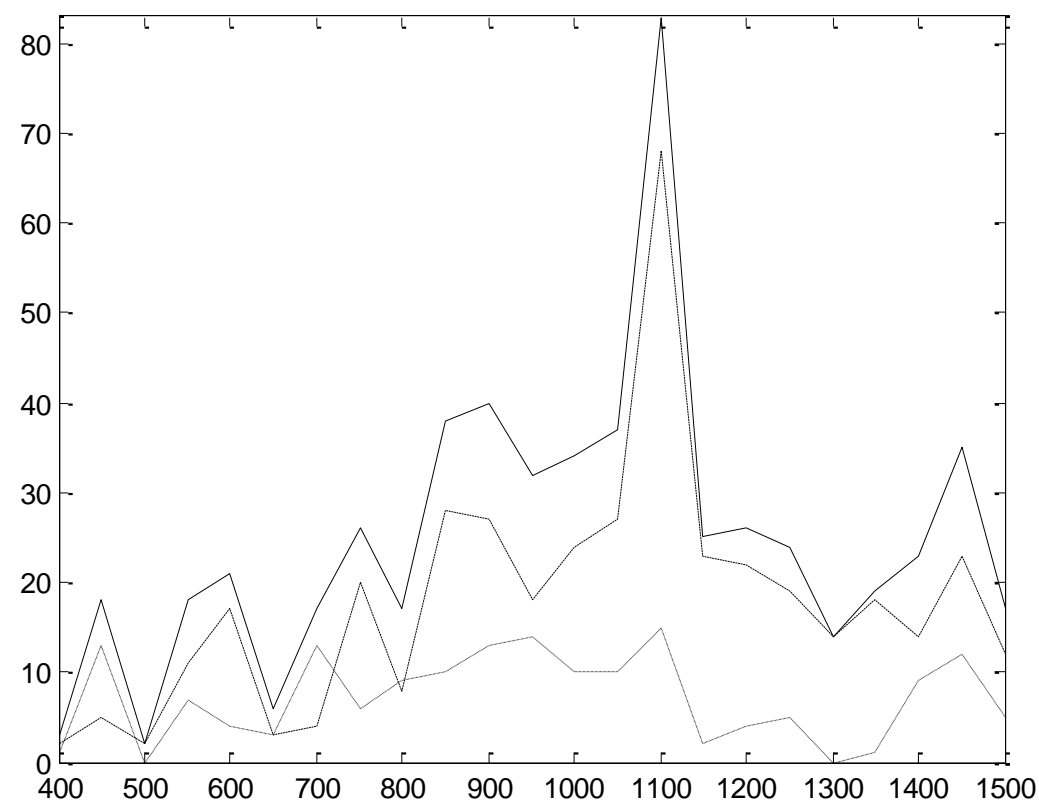

Figure 2. Temporal variation of the number of meteor records throughout V-XVth centuries. The solid line represents the totality of data, the dashed line stands for the European+Arabic data. The dotted line is used for the oriental data in which Biot's data of sporadic meteors have been excluded.

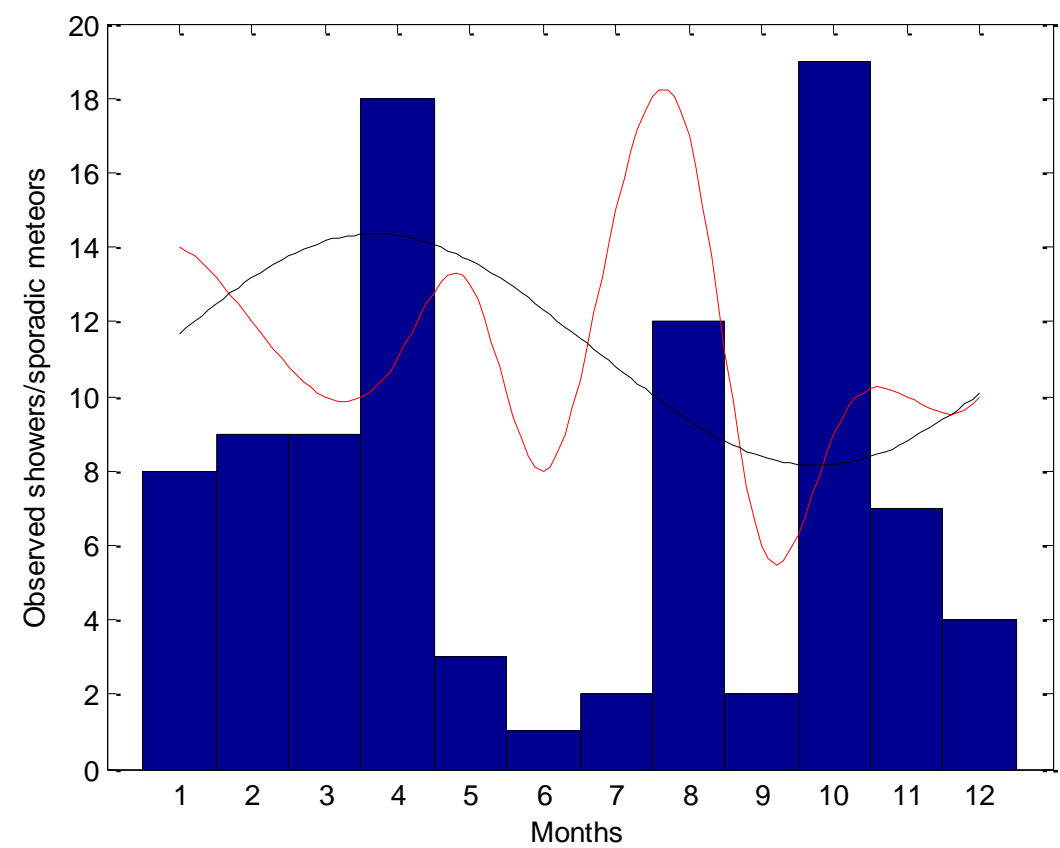

Figure 3: Distribution along the year of European data. The bars represent the showers. The red solid line represents the number of accounts of sporadic meteors. The black solid line is the fitting curve of the annual variation of sporadic meteors. 
In figure 3 we see the distribution along the year of the European data. The bars represent the showers. At first sight, three identifications seem clear: April Lyrids / eta Aquariids, Perseids, and Leonids. The red line represents the accounts of sporadic meteors. The black solid line is the fitting curve of the annual variation of sporadic meteors. The seasonal variation of the historical meteors roughly agrees with that of current observations if we disregard the bias caused by the observations of sporadic meteors around the dates of the main showers. It has been stated by Yrjölä \& Jenniskens (1998) that this sporadic activity is well represented by the equation:

$$
N\left(H, \lambda_{\odot}\right)=\left\langle N_{s p o}\right\rangle(H)-\Delta N_{s p o}(H) \cos \left(\lambda_{\odot}\right)
$$

where $\left\langle N_{s p o}\right\rangle$ is the mean daily sporadic hourly count at the summer solstice and $\Delta N_{s p o}$ is the yearly amplitude due to seasonal variation at a given local time $(H)$ and $\lambda_{\odot}$ is the solar longitude. Rates are expected to peak around the Autumnal Equinox and to be lowest around the Vernal Equinox in the Northern Hemisphere. We have included in Figure 3 a fitting curve of the annual variation of sporadic meteors that is in rough agreement with the observed sporadic meteors records. Most records do not have the detailed description that is needed to apply formula (1) so we have used a simplified form of this equation given by:

$N\left(\lambda_{\odot}\right)=\left\langle N_{s p o}\right\rangle-\Delta N_{s p o} \cos \left(\lambda_{\odot}\right)$

When we are dealing with such long periods of time, we must take into account that Historical records are affected by the climate of the place of observation. Yang et al (2005) stated that climate reasons there is an excess of observations from September to March relative to from May to August in Korea. Mediterranean countries are usually affected by covered skies around the equinoxes and Northern countries have difficult observation conditions in winter.

Regarding the sporadic meteors, we are now going to consider the totality of data from Korean, Japanese, Chinese and Arabian sources. We see in figure 4 its distribution along the year. The seasonal variation in the sporadic meteor activity is caused by the seasonal variation of the highest rising radiant due to the changing direction of the apex of the Earth's orbit. On the horizontal axis, we represent the solar longitude at the time of that year to the appearance of meteors. The vertical axis is the number of events. The solid line represents the totality of data, the dashed line stands for the European+Arabic data. The dotted line is used for the oriental data. The peaks for Perseids and Leonids give a significant maximum for those longitudes, but we see that the mean activity is roughly in agreement with the expected rates as given by equation (2). It is worth remarking that as seen from the northern hemisphere, March $\left(\lambda_{\odot} \approx 0^{\circ}\right)$ is the slowest month for meteor activity. No major annual showers are active and only a few very weak minor showers produce activity this month. The sporadic rates are also near their annual minimum so there is not much to look forward to this month except for the evening fireballs that seem to peak this time of year as seen from the northern hemisphere. 


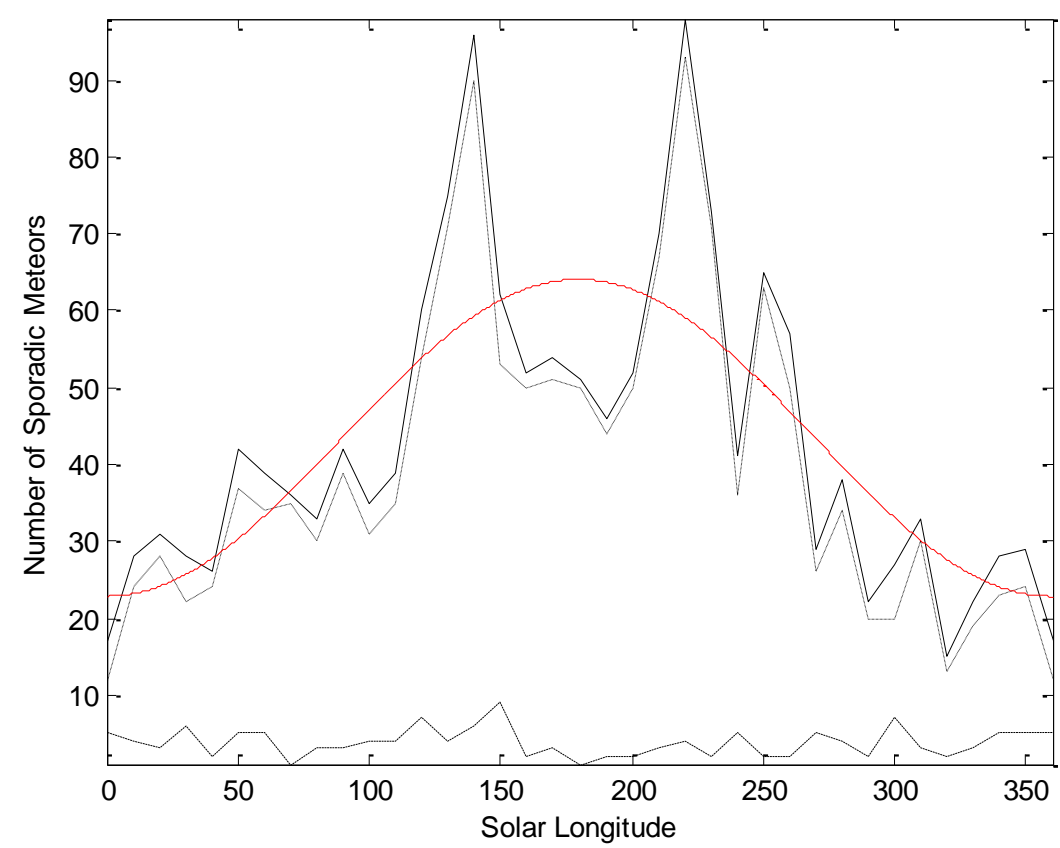

Figure 4. Annual sporadic meteoric activity during the considered period. On the horizontal axis, we represent the solar longitude at the time of that year when meteors appear. The vertical axis is the number of events. The solid line represents the totality of data, the dashed line stands for the European+Arabic data. The dotted line is used for the oriental data. The red line represents the calculated curve given by (2)

In figure 5 we see the distributions of the showers along the year using the solar longitude as the parameter. The names at the top of the figure correspond to the established positions of the current major showers: LYR, ETA, PER, ORI, TAU,LEO, GEM, URS, QUA stands for Lyrids, Eta Aquarids, Perseids, Orionids, Leonids, Geminids, Ursids, and Quadrantids, respectively. Initially, it seems clear that Lyrids, Orionids, Taurids, Leonids, Ursids, and Quadrantids are present, while Eta Aquarids and Geminids are absent. We will deal with this issue in the next section. 


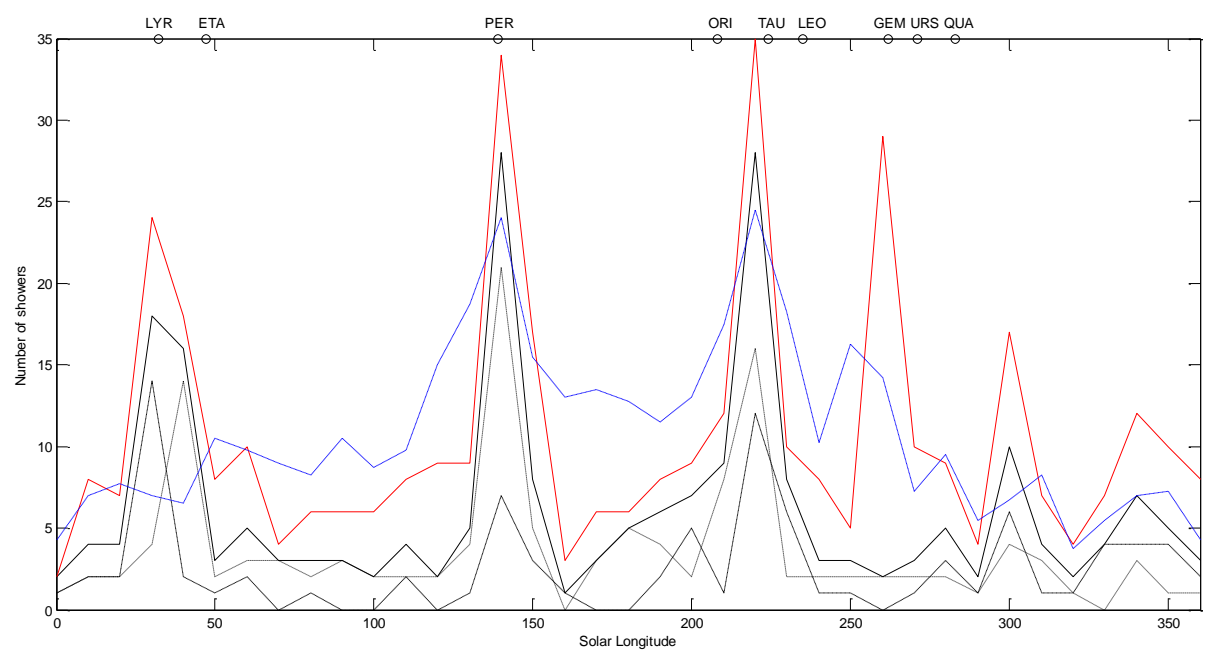

Figure 5 Annual meteoric showers during the considered period. On the horizontal axis, we represent the solar longitude. The vertical axis is the number of events. The solid line represents the totality of data, the dashed line stands for the European+Arabic data. The dotted line is used for the oriental data. In red, we have plotted the European+Arabic sporadic meteors and the blue dashed line represents the total reports of sporadic meteors. In order to maintain the scale, these last values have been divided by 4 .

A first approximation to the results provide significant differences with respect those studies by other authors: Hasegawa (1992), Ahn (2003), Yang et al. (2005) and Jenniskens (2006, p 7) identify Perseids and Leonids, but do not record the Quadrantids (at the beginning of January). The complex Leonids+Taurids gains relevance in our results with respect to the others authors and some minor peaks appear more clearly. On the contrary, other significant minor peaks seem to have been missed.

These authors use different methodology to analyze their results: Hasegawa (1992), plotted monthly variations of meteors for each century after 1001AD, using the tropical year as the unity of time. Ahn (2003) define the number of days after the perihelion passage time of the year i.e. the anomalistic year and plots the results using a bin size on the horizontal axis of 4 days. Yang et al. (2005) use the sidereal year as the basic period for yearly meteor showers and plot their results with a bin of 5 days and when the reports given in their data only provide year and month (without the day) they smooth all records over the corresponding lunar month. Jenniskens (2006) gathers together all the information obtained from several authors and plots them using months as the bin for the horizontal axis. He reaches the conclusion that Quadrantids and Geminids were absent in the Middle Age. In some cases, when the complete date of the event is missed, these authors take approximate dates.

In our case, we only consider those events with complete date (year, month and day) and we consider the solar longitude as the basic unit of the horizontal axis and take bins of 10 degrees, that roughly mean 10 days in order to avoid undesired oscillations that, due to the relatively small quantity of data we consider of minor significance. In next section, we will study each peak separately and compare our results with those of these authors. 


\subsection{Meteor showers}

Annual streams are those streams that occur each year when the Earth passes the orbit of the parent comet. The meteor's rates are variable in function of the position of the Earth. They increase until they reach a peak and then decreases. A very good description of the ideal observation conditions and the corrections that should be applied to the observations is given by Jenniskens (1994) However, our data lack of information such as the time of the day, altitude of the radiant and ZHR (Zenital Hourly Rate) in the case of star showers and meteorological conditions, so our analysis is, necessary, limited.

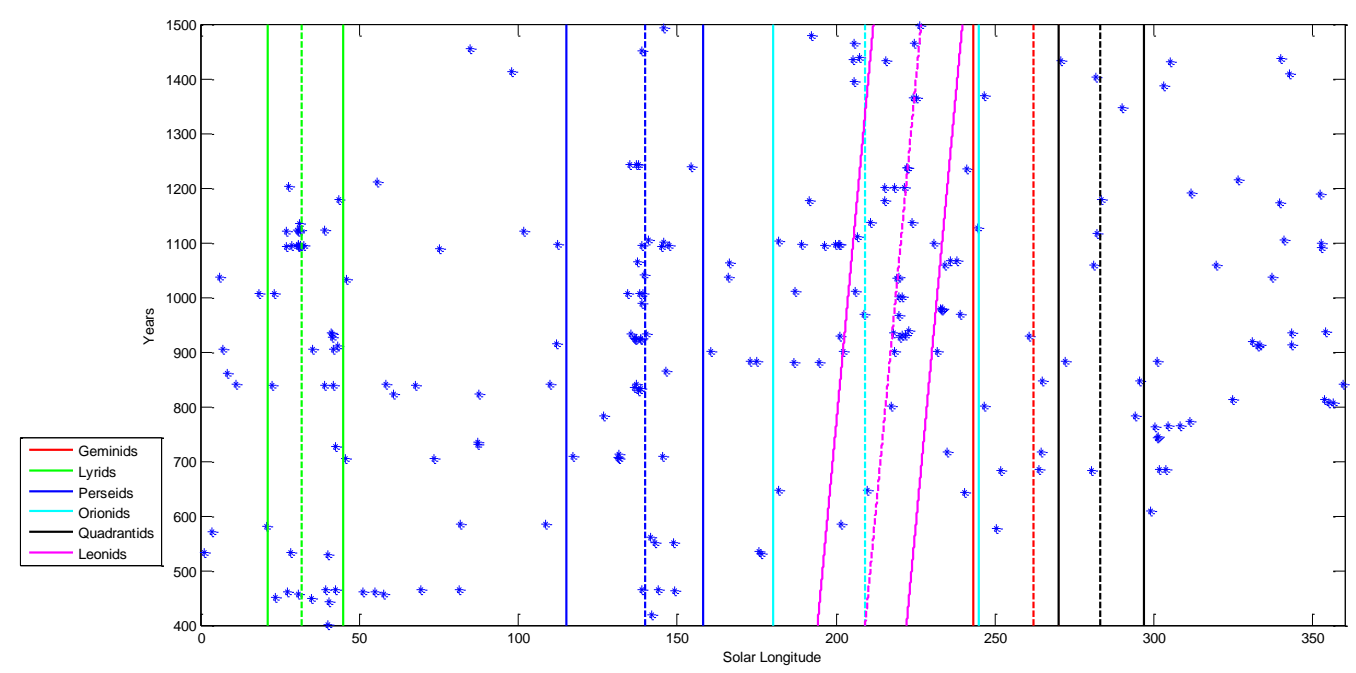

Figure 6: Distribution of the reported meteor showers and comparison with the modern dates of the currently established main meteors showers.

We will focus on Figures 5 and 6 to propose identifications of meteor showers. From figure 6 some identifications are evident because most reported events fall in the maximum of a current meteor shower; while in figure 5, if we consider the total amount of meteor showers (red line), we distinguish three major peaks and other two minor peaks of activity. However, in a further analysis, we will consider other major peaks taking into account the sporadic meteors, as seen in table 1, where we summarize the results. We provide the interval of solar longitude where the increment of meteoritic activity was observed in figure 5, the solar longitude of the maxima and the tentative identification. The number next to the name of the shower corresponds to the IAU identification (Jopek \& Kaňuchová, 2017). 


\begin{tabular}{|c|c|c|c|}
\hline \multicolumn{4}{|c|}{ Major Peaks } \\
\hline$\lambda_{\odot} \min$ & $\lambda_{\odot}$ peak & $\lambda_{\odot} \max$ & Temptative Identification \\
\hline $20^{\circ}$ & $30^{\circ}$ & $50^{\circ}$ & $\begin{array}{l}6 \text { April Lyrids } \\
31 \text { eta Aquariids }\end{array}$ \\
\hline $130^{\circ}$ & $140^{\circ}$ & $150^{\circ}$ & 7 Perseids \\
\hline $200^{\circ}$ & $220^{\circ}$ & $230^{\circ}$ & $\begin{array}{l}13 \text { Leonids } \\
17 \text { Northern Taurids }\end{array}$ \\
\hline $250^{\circ}$ & $260^{\circ}$ & $270^{\circ}$ & $\begin{array}{l}256 \text { Northern Chi Orionids } \\
4 \text { Geminids } \\
19 \text { December Monocerotids }\end{array}$ \\
\hline \multicolumn{4}{|c|}{ Minor Peaks } \\
\hline$\lambda_{\odot} \min$ & $\lambda_{\odot}$ peak & $\lambda_{\odot} \max$ & Prob Ident. \\
\hline 50 & 60 & 70 & $\begin{array}{l}31 \text { eta Aquariids } \\
145 \text { eta Lyrids }\end{array}$ \\
\hline 100 & 110 & 120 & $\begin{array}{l}175 \text { July Pegasids } \\
326 \text { Epsilon Pegasis } \\
328 \text { Alpha Lacertis } \\
411 \text { c Andromedids } \\
444 \text { zeta Casiopeiids }\end{array}$ \\
\hline 190 & 200 & 210 & $\begin{array}{l}9 \text { October Draconids } \\
23 \text { Epsilon Geminids }\end{array}$ \\
\hline 270 & 280 & 290 & $\begin{array}{l}10 \text { Quadrantids } \\
15 \text { Ursids }\end{array}$ \\
\hline 290 & 300 & 310 & $\begin{array}{l}90 \text { January Comae Berenicids } \\
530 \text { Eta Corvids } \\
404 \text { Gamma Ursae Minoris. }\end{array}$ \\
\hline 330 & 340 & 360 & $\begin{array}{l}733 \text { Lambda Leonids } \\
346 \text { eta Aquariids }\end{array}$ \\
\hline
\end{tabular}

Table 1: Peaks in figure 5 and possible identifications. The numbers of the showers correspond to the IAU nomenclature.

In order to study possible evolutions of the meteor showers, we have included in Figure 7 the distribution of all the data, not only European, for the 400-700, 700-1000, 10001300 and 1300-1500 years periods. Only the showers have been included. 

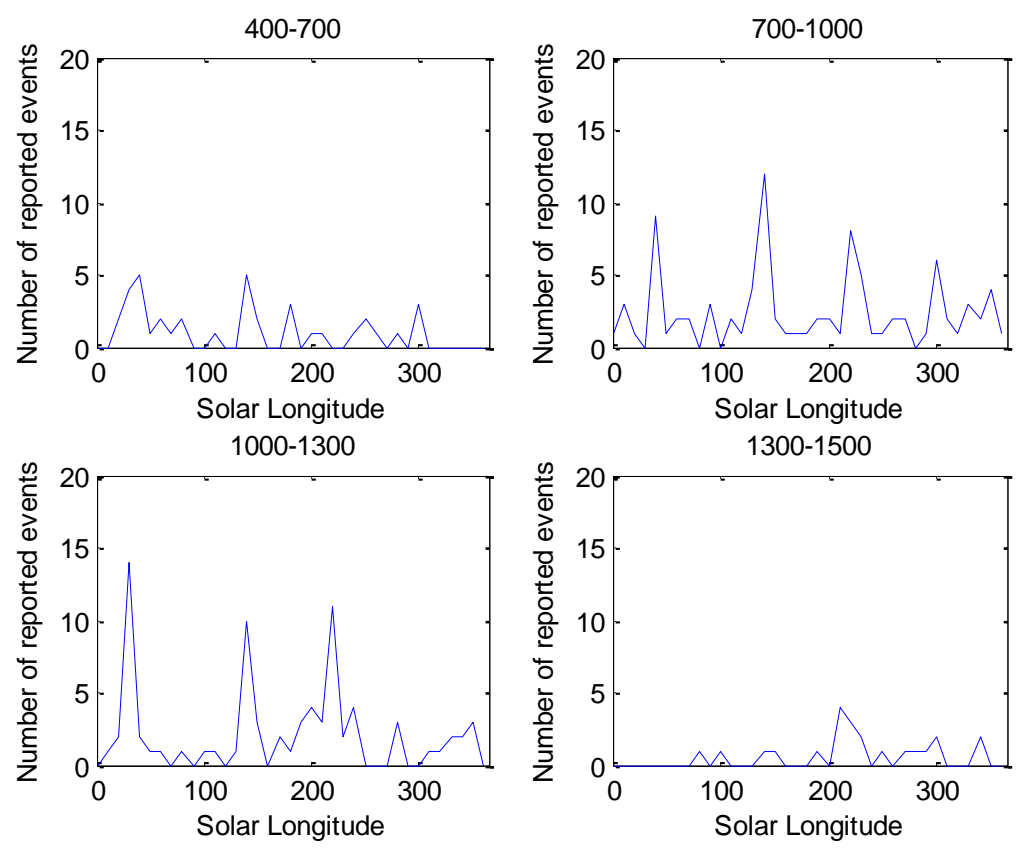

Figure 7: Distribution in centuries of the total of meteors showers. Sporadic meteors are disregarded in this figure.

\subsubsection{Major showers}

1. The first important peak corresponds to a solar longitude of $\lambda_{\odot}=20^{\circ}-50^{\circ}$ with a maximum at $\lambda_{\odot}=30^{\circ}$. Ahn (2003) detected this peak and assigned it to the eta Aquariids. In our opinion, the length of the maximum is too broad in time to be assigned to a lonely shower. In addition, the maximum of the peak occurs at $\lambda_{\odot}=30^{\circ}$, too early to be the eta Aquariids, but then there is a change of the slope at $\lambda_{\odot}=40^{\circ}$ that roughly coincides with their maximum. So, in this case, our proposed identification is the overlapping April Lyrids and eta Aquariids.

Lyrids belong to the established long period comet showers beings its parent comet C/1861 G1 Thatcher and are currently active around April 18-25 with a Peak Activity on April 22-23. Astapovic \& Terenteva (1967) concluded that there was no significant evolution of the node along time. The peak rates of activity have remained relatively consistent from year to year with values generally between 5 and 10 per hour, although there have been unexpected outbursts. Regarding its orbital period, several authors have attempted to provide an accurate estimation. One of the most recent is given by Arter \& Williams (1997) who suggested the presence of clumps of meteoroids following an approximate 12 -yr period. The $20^{\text {th }}$-century outburst dates suggest that they occur at time intervals that are multiples of about 12 yrs. Outbursts of activity are also known in other meteor showers, the best known being the Leonids and the Draconids. In both these showers, the generally accepted explanation is that outbursts are correlated to the close proximity of the parent comet to the Earth. This explanation cannot be used for the April Lyrids because their parent comet C/1861 G1 (Thatcher) has an orbital period 
of $415 \mathrm{yr}$ hence proximity to the Earth cannot come about every $12 \mathrm{yr}$. Instead, it has been suggested a period of $60 \mathrm{yr}$ (Jenniskens, 1997). Finally, Brown et al. (2010) determined a period of about 36 years. It is out of the scope of this paper, but from figure 6 we can see several clear outburst periods, some of them fitting the proposed 60 years period. It is noteworthy the ones around years 460,1095 and 1122 with a $\lambda_{\odot}=26^{\circ}$ maybe a further careful examination of these dates could provide light to the issue of the Lyrids period.

Yang et al (2005) also identify this peak in their Chinese and Korean records, but they disregarded its association to the eta Aquariids, because of its disappearance after the XIVth century and the awakening of the shower in the IX-XIIIth centuries. We have not found such weakening, and, although the disappearance of the shower in later dates is visible in figure 7 , this may be explained by the diminution of the quantity of data. Astapovic \& Terenteva (1967) concluded very low activity for the eta Aquarids in the VIII-XIth centuries, but our data seem to point out to some outburst around years 450 , $700,850,900-950$ and 1040. It is of special interest the reports around the years 451 and 837 (see Figure 6) when Halley's comet reached its perihelion. With the exception of years 900-950, they do not seem to have their counterpart as Orionids but it is possible that a minor peak around $\lambda_{\odot}=200^{\circ}$ belongs to observations of the Orionids. In any case, this peak appears only for the European data (see figure 5) although the rise provided by the maximum of the Perseids may mask these observations.

2. In the second place, we find a peak at $\lambda_{\odot}=140^{\circ}$ corresponding to the Perseids, whose parent body is comet 109P/Swift-Tuttle. They are currently active from July 13 to August 26 with a peak of activity on August 11-12.

European observations of Perseids seemed absent in all the previous studies of ancient meteor showers. We have found a number of showers and isolated meteors from the Vth to the XVth century (Martinez \& Marco 2017) that could correspond to this shower. This peak also appears in the studies of all the considered authors and all of them suggested a reduction of the Perseids activity that is also noticeable in our data (see figure 7)

A study of the past and future orbit of comet 109P/Swift-Tuttle was carried out by Yau et al (1994). In figure 8 we see the distance from the nucleus of this comet to the Earth at the position of the ascending node. The asterisk represents a reported meteor storm. The distance has been computed using HORIZONS Web interface (http://ssd.jpl.nasa.gov) from the JPL. We see that the showers do not always coincide with the moment of the maximum proximity of the comet to the Earth, showing a nonuniform distribution of the debris in its orbit. 


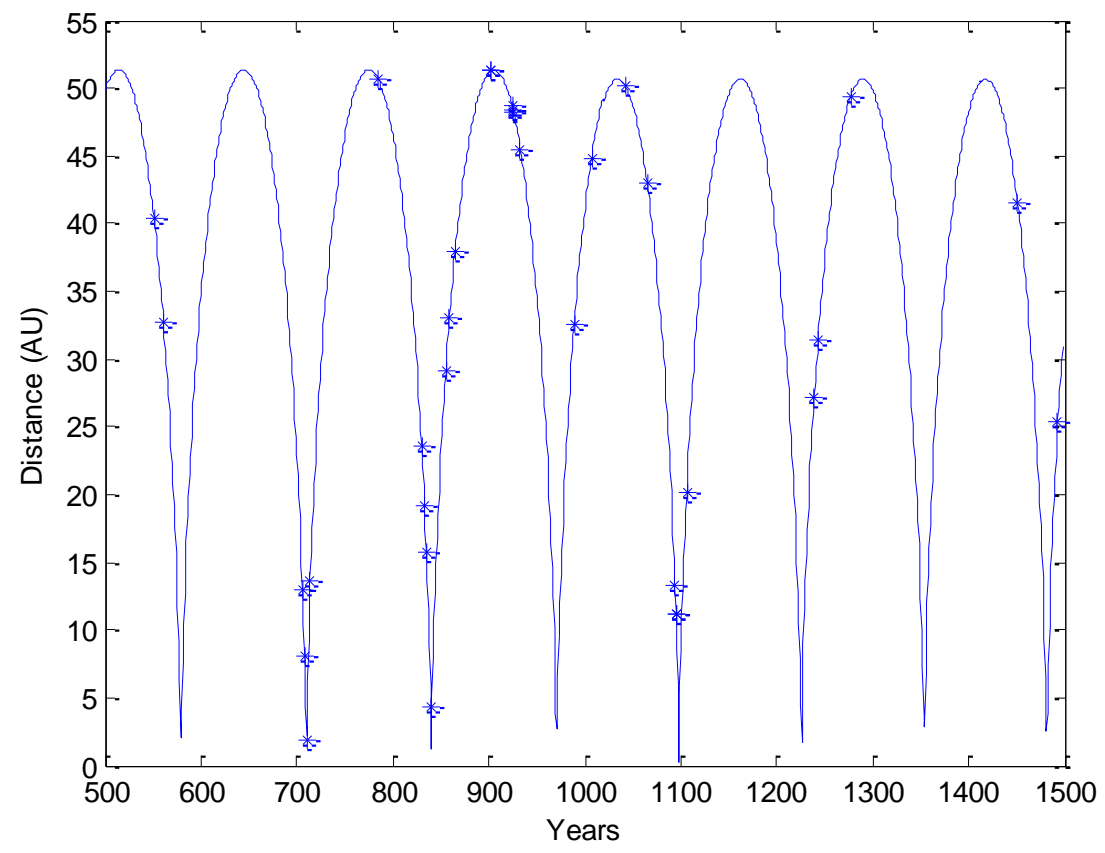

Figure 8. Distance from the nucleus of comet 109P at the moment when the Earth is in its ascending node. The asterisks represent a reported Perseids meteor storm.

Astapovic \& Terenteva (1967) found no significant change in the node from the IX to this century. Hughes \& Emerson (1982) proposed a rate of $0.038 \pm 0.027 \%$ cent Jenniskens (1994) provides $0.47 \pm 0.05 \%$ cent for recent years. Using our data (see figure 9) from year 400 onwards we have obtained a rate of $0.09 \pm 0.2 \%$ cent with a solar longitude for the maximum of $\lambda_{\odot}^{\max }=138^{\circ} .32 \pm 0.68^{\circ} / \mathrm{c}$ for year 400 .

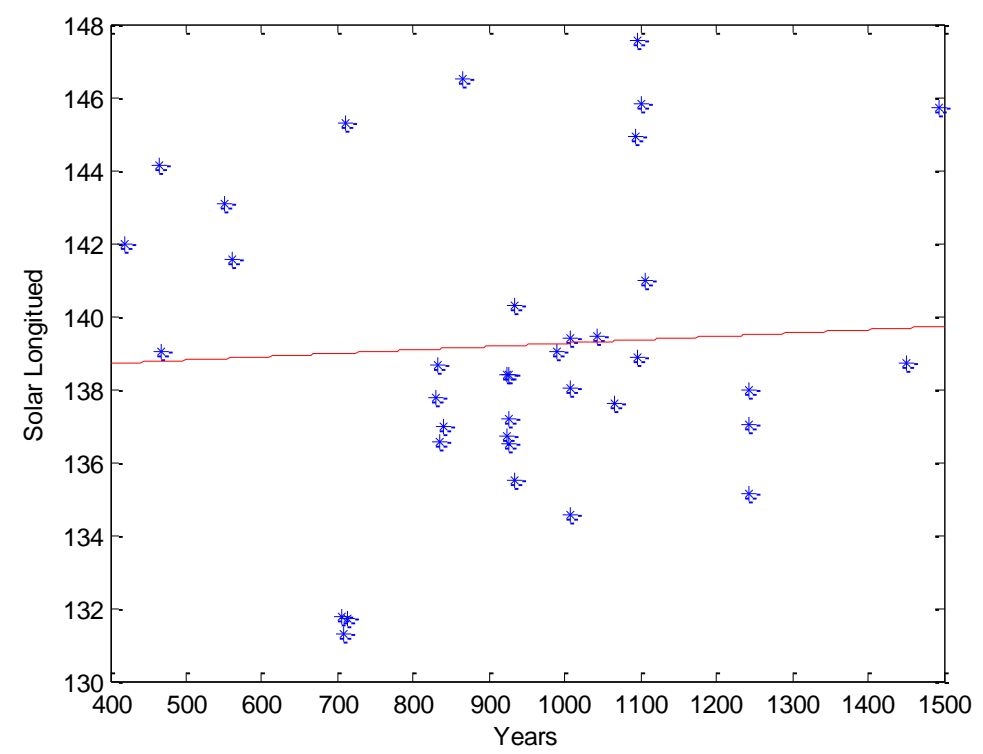

Figure 9: Distribution of Perseids showers from 400 to 1500. The solid red line represents the linear regression. 
3. The third peak belongs to the overlapping Leonids and Taurids (Northern Taurids). It is displaced from the current maximum of the Leonids due to the nodal displacement. This is one of the best-known and studied annual showers. Its outburst the night of 12 November 1833 represented not only its official discovery but also the beginning of the systematic study of the meteors.

The existence of the November shower for the Medieval period was already studied and demonstrated by Ahn (2003) who concluded that the overlapping Leonids and Taurids were the responsible of these showers. Hasegawa $(1992,1998)$ studied the November meteors shower using Chinese observations and then including the Koryo meteor records and proposed that they correspond to the Taurids. Leonids and Taurids are also present in Korean and Chinese records studied by Yang et al. (2005)

Currently, Leonid Meteor shower is visible around Middle November, peak activity occurs from November 17-18, with a solar longitude of $235.3^{\circ}$. The periods of enhanced activity occur in intervals of approximately 33.2 years, in agreement with the orbit of its parent comet 55P/Tempel-Tuttle. These periods of great activity usually extend from two years before to five years after the comet's perihelion passage, due to planetary perturbations and the uneven dust distribution on the orbit of the parent comet. However, the parent body of the Leonids has a retrograde orbit that it is close to the ecliptic plane. Its orbit precesses by no more than $\frac{d \Omega}{d t}=+0.0008^{\circ} / y r$, according to Jenniskens (1995), and this causes the shift of its nodal point along the Earth's orbit. A consequence of this is the date of the occurrence of the Leonids changes in time, from the current middle November to October. Yeomans et al. (1996) recomputed the orbit of this comet for two millennia. We have computed the distance of the nucleus of comet 55P to the Earth for the years 800-1500 at the moment when the Earth is in the descending node using the HORIZON program of the JPL (see figure 10). The asterisks represent a reported meteor shower.

There is no definitive observation of comet Tempel-Tuttle prior to 1366, with a possible Japanese record on 1234 October 30 (Ho, 1962) but the comet debris has been observable since at least $902 \mathrm{AD}$ and we have found a few four possible observations of Leonids before this date. 


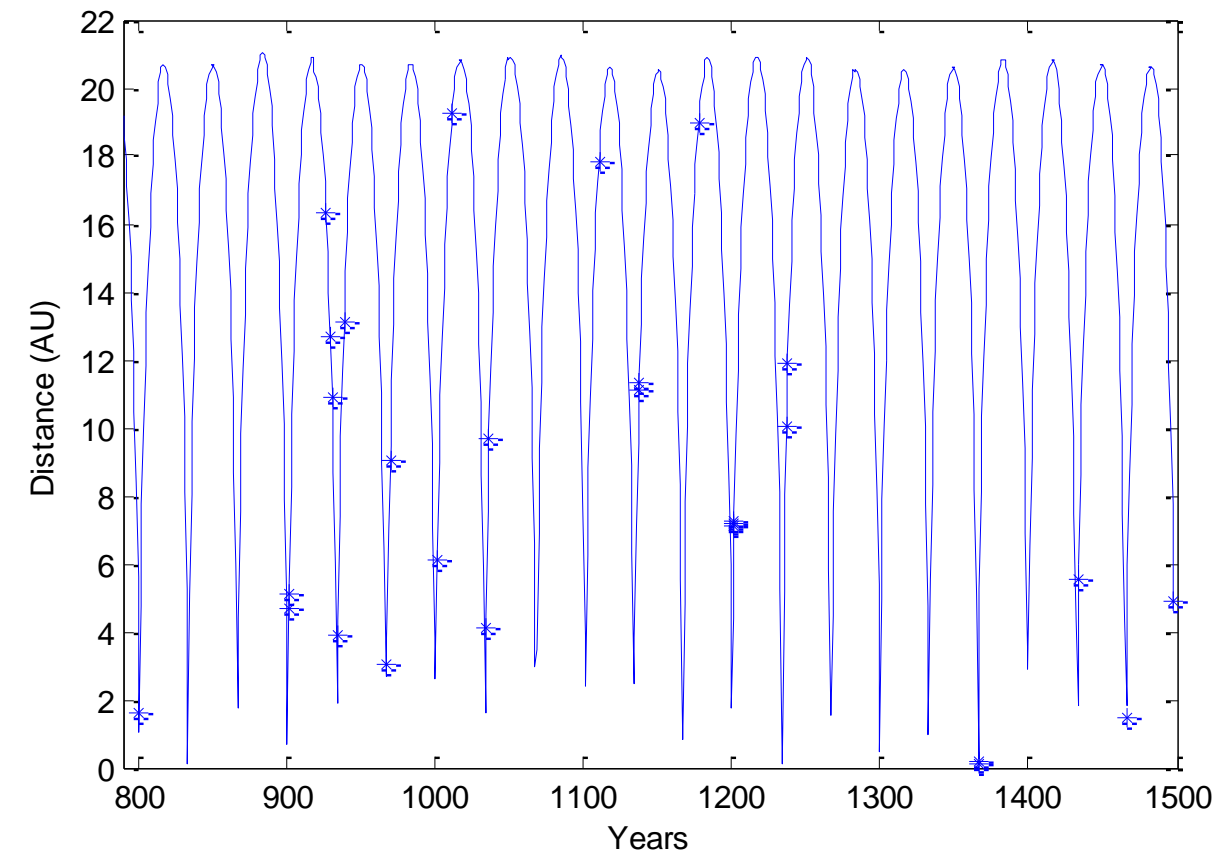

Figure 10. Distance from the nucleus of comet 55P to the Earth at the moment when the Earth is in its descending node. The asterisks represent a reported Leonid meteor storm.

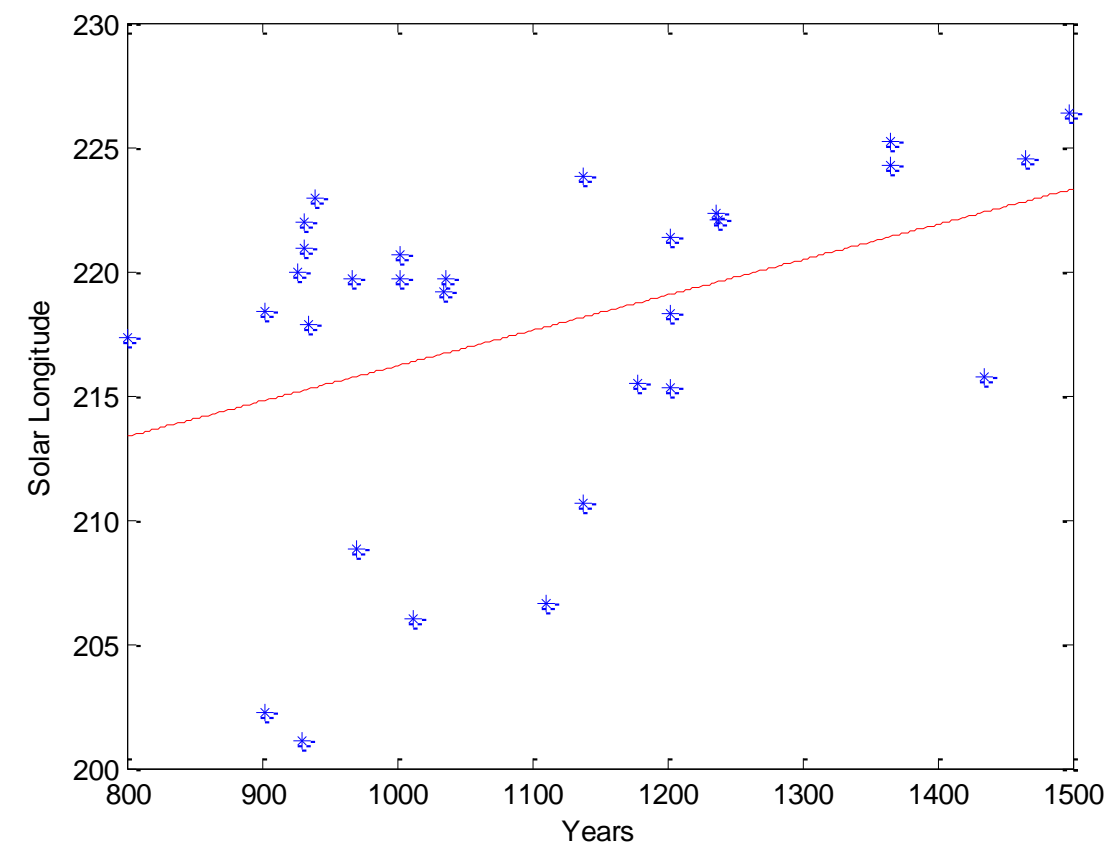

Figure 11. The shift of appearance dates of the Leonid Meteor showers. The red solid line corresponds to the linear regression. 


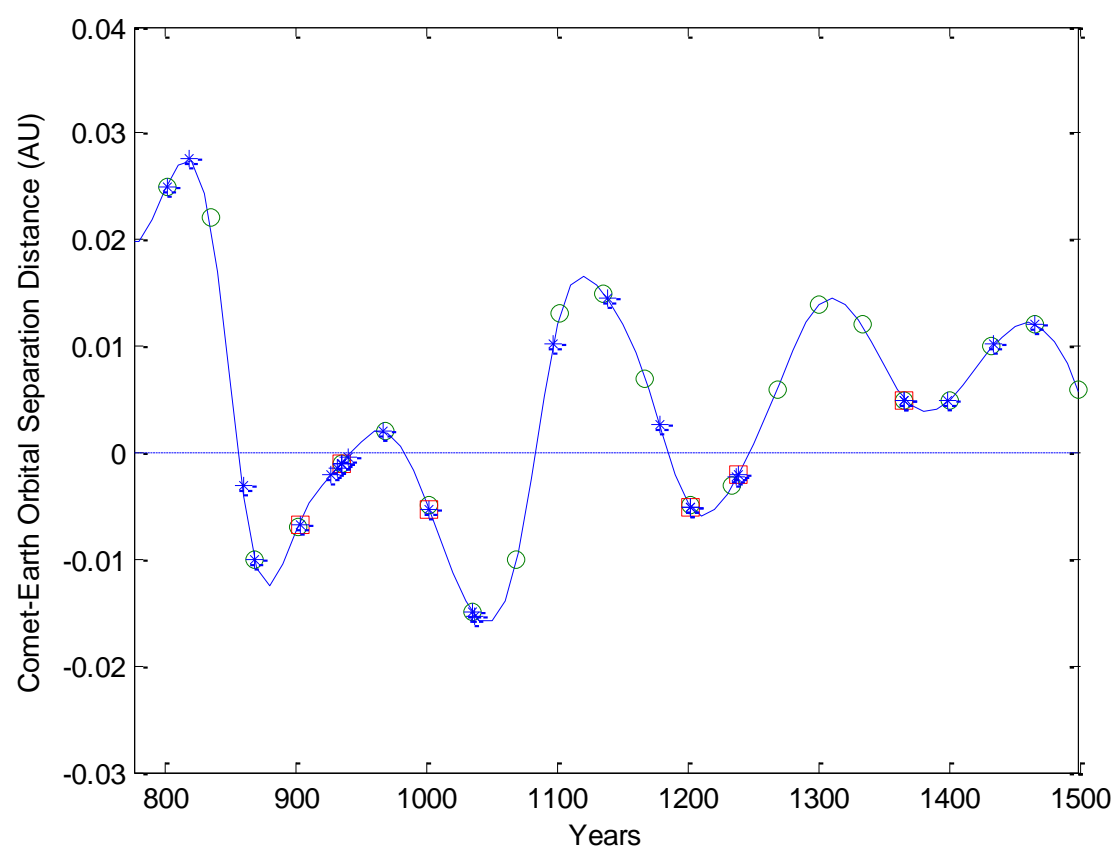

Figure 12: Minimum distance between the comet 55P/Tempel-Tuttle and the Earth's orbit at the time of the comet's passage through its descending node (modified from Yeomans et al. (1996)). The circles represent the date of the perihelion and the asterisk is a reported meteor shower. A red square represents an outstanding meteor shower (meteors outbursts).

We plot in Figure 11 the historical records of the Leonid Meteor showers and outbursts for the period between year 800 and 1500 . We have fitted a least squares line (red line in Figure 11) and we have obtained that

$$
\Omega(t)=\left(1^{\mathrm{o}} .42 \pm 0.62^{\mathrm{o}}\right) t+\left(201^{\mathrm{o}} .95 \pm 1^{\mathrm{o}} .14\right)
$$

where $t$ represents the year. The solar longitude obtained for the maximum in year 800 is $\lambda_{\odot}=213^{\circ}$ and for the middle of the XI century, we obtain $\lambda_{\odot}=217^{\circ}$, in agreement with the work of Astapovic \& Terenteva (1968) who obtained a value of $220^{\circ}$ (B1950.0). The nodal advancement rate of the meteor stream is estimated in $1^{d} .457 \pm 0^{d} .027$ per century by Toth (1999) and Newton (1864) estimated the nodal advancement of the comet $55 \mathrm{P}$ to be $1^{d} .475$ per century. From historical and recent observations, Toth (1999) obtained a value of $1^{\circ} .4360 \pm 0^{\circ} .0268$ per century. Astapovic \& Terenteva (1968) analyzed the trajectories of fireballs recorded in the 'General study of the literary remains' and obtained the radiants or ancient meteor showers between the $1^{\text {st }}$ and the XVth centuries. Their value for the shift of the orbital node of the Leonids was $1.6^{\circ}$ per century.

We can also make a further study taking into account the work of Astapovic \& Terenteva (1968) and Hasegawa (1992) who suggest that the activity of the Taurids may have been comparable to the Perseids of today. We can try to discriminate between them and to this aim we have also performed a simple weighted least squares 
computation assigning minor weights to those observations that had a solar longitude coincident with the Taurids. In this case, we have obtained a value of $1^{\circ} .2 \pm 0.1^{\circ}$ with an initial solar longitude of $\lambda_{\odot}=213^{\circ}$ for the year 800. A good review of the most prominent studies on this meteor shower is can be found in Kronk (2014)

Yeomans et al. (1996) stated that no Leonid meteors shower should have been visible prior to the eighth century because the comet's orbit passed too far away that of the Earth and our data support this statement. In addition, significant Leonid appearances are possible around 2500 days before or after the perihelion, but only if the comet passes closer than 0.025 AU inside or 0.010 AU outside the Earth's orbit. In Figure 12 we have checked that this assumption is verified. We have plotted the minimum distance between the comet Tempel-Tuttle and the Earth's orbit at the time of the comet's passage through its descending node. The circles represent the date of the perihelion and the asterisk is a reported meteor shower. A red square represents an outstanding meteor shower (meteors outbursts).

4. Not many meteor showers were reported around $\lambda_{\odot}=260^{\circ}$ but there is a sharp increment in the observations of sporadic meteors and bolides. In fact, a conspicuous peak appears that almost coincides with the currently expected for the Geminids. Current active showers point to Geminids and $\chi$ Orionids. Geminids has 3200 Phaeton as the parent body. According to Astapovic \& Terenkeva (1968), Gemínids reached its peak of activity about the $13-14^{\text {th }}$ December in the XIth century. Jenniskens (1994) states that there is not a significant shift from its discovery at the beginning of the XIX century which is in agreement with Astapovic \& Terenteva (1968). The current rate of activity is 120 meteors/hour. However, further studies have shown that the orbits of the Geminids stream and the Earths had no intersection at the time that we are studying, so no observable meteor shower could have happened (see Fox et al. 1982, 1985).

Also according to Fox et al (1985) and Hasegawa (1999), December Monocerotids and not Geminids were responsible for most of the bolids observed in December in the XIth centuries. Fox et al (1985) reached this conclusion after integrating the orbit of comet Mellish. And Hasegawa (1999) concluded that this shower was active in medieval and ancient times. The authors concluded that an explanation should be found to the inactivity of this shower from the XIth century. But in figure 1, we see that this shower was already detected in the period 1000-1300 and reached a considerable activity in the 1300-1500 period.

In addition to December Monocerotids, $\chi$ Orionids (Ahn, 2003) and December Alpha Draconids are also two sources of possible meteors for this date.

\subsubsection{Minor showers}

Other minor peaks appear in figure 5 that could correspond to minor or now extinct showers. The first one is around $\lambda_{\odot}=60^{\circ}$. According to Jenniskens et al (2016), two possible recent showers could fit this solar longitude: eta Lyrids and epsilon Aquilids. 
But the existence of these weak showers is uncertain and also other authors have not detected it.

Next peak appears around $\lambda_{\odot}=110^{\circ}$. This could also be a spurious maximum. However, as the solar longitude do not correspond to the June Bootids, the possible identification according to de data from to Jenniskens et al (2016), with current meteor showers are 175 July Pegasids, 326 Epsilon Pegasi, 328 Alpha Lacertis, 420 c Andromedids and 444 zeta Casiopeiids.

Next maximum is only evident for European data, at a solar longitude of $\lambda_{\odot}=200^{\circ}$. As previously stated, this could be the Orionids, but we can also take into account the possibility of the Draconids o Giacobinids, which are associated to comet P/GiacobiniZinner $1913 \mathrm{~V}$, but they reach its maximum at about $\lambda_{\odot}=195^{\circ}$ and have a small activity window. Wu \&William (1995) pointed out that the characteristics of the Draconids suggested a relatively new shower so that it would not have detected as early as the VthXVth centuries. However, Fisher (1934) investigated the relative positions of the Earth and the comet and concluded that some showers could have been already recorded in the VIth century.

The maximum at $\lambda_{\odot}=280^{\circ}$ may be assigned to Quadrantids and Ursids. Quadrantids are controversial in the sense that there is no complete agreement about the age of the meteor stream, but this is the best fit from the list given by Jenniskens (2016). Its parent body is 2003 EH1 (Jenniskens, 2006 and the approved by the IAU in 2008). Until its discovery, the parent of the Quadrantid shower was thought to be lost from the stream. At the beginning, some authors (Astapovic \& Terenteva, 1958), (Williams et al. 1979) claimed that Quadrantids is an old shower. Others credit it an age of only four centuries (Jenniskens et al, 1997), Wieger \& Brown (2004) stated that the core of the Quadrantid was no more than 200 years old, Abedin et al (2016) stated that the central portion of the Quadrantid meteor stream was indeed 200 years old.

Hasegawa (1979) pointed out that Chinese, Korean and Japanese observers recorded a bright comet in January of 1491 (C/1490 Y1) with an orbit similar to that of the Quadrantids. This link, as well as the connection to comet 96P/Machholz could provide a much older shower.

Ursids is another possibility for the showers sited at the lower part of this period. Fox (1986) concluded that in year 950 the shower's maximum would have occurred 6 days later than at present, which means at about the date of our peak.

Next peak corresponds to $\lambda_{\odot}=300^{\circ}$, that seems to fit the Northern Delta Cranquids and Southern Delta Cranquids. Ahn, (2003) doubts about the identification, but proposes February eta Draconids, even when the most likely possibility is that these weak peaks are aged and depleted showers or relics of dead comets. The end of January and February are currently bad months for meteor showers so our guess for the sharp 
increment observed for this date would also be an extinct shower. However, three possible minor showers would also be January Comae Berenicids, Eta Corvids, and Gamma Ursae Minoris, but in this case, the responsible shower should have experimented an increment in its ZHR.

The last peak corresponds to $\lambda_{\odot}=340^{\circ}$, again a part of the year when meteor showers are scarce nowadays. Our guess is again an extinct shower. Current showers for this epoch Lambda Leonids and eta Aquariids even when this last shower is mainly a southern shower and observers in the Northern Hemisphere do not usually obtain good rates of meteors.

\section{Conclusions}

We have investigated the sporadic meteors and showers in the Medieval European records for the years 400-1500. We have found that the seasonal activity of sporadic meteors shows rough agreement with modern observation. We have also found that there were a few prominent meteor showers and storms that correspond to the current ones: Perseids, Leonids, Lyrids and, possibly, eta Aquarids/Orionids pair. There were also weak and aged meteor showers. The meteor showers are in good agreement with the meteor storms compiled from the worldwide chronicles, as well as with modern observation.

We have compared our results with those of Hasegawa (1992), Ahn (2006) and Yang et al (2005). All these authors took into account mainly Asian records, mainly because of the little amount of data from European and Arabian sources. We have carried out a study with the new enlarged European data provided by Martínez \& Marco (2017).

We have arranged a more careful study of the Perseids and Leonids, obtaining the regression of the nodes and we have checked that our results coincide with the expected values. Our conclusions are that the major meteor showers and storms for the V-XV period might be caused by the same short-period comets as the current ones, and the data seem to point to at least two extinct meteor showers with a peak of activity around the end of January and the beginning of March. In addition, most of the weaker (but still important) showers such as Geminids and Ursids, seem to have a lower activity range or not have been observed at all.

\section{References:}

Abedin A. Spurný P., Wiegert P., Pokorný P, Borovicka, J., Brown P., 2015, Icarus, 261, p 100 Ahn Sang-Hyeon, 2003, MNRAS, 343, p 1095

Ahn Sang-Hyeon, 2004, Earth, Moon and Planets. 95, p 63

Ahn Sang-Hyeon, 2005, MNRAS, 358, p 1105

Alter T.R, Williams I.P., 1997, MNRAS, 286, p 163

Astapovic I.S., Terenteva A.K. (1967) in Kresác and Millman (eds) Physics and Dynamics of Meteors., p 308

Basurah, H.M., 2012, arXiv:1210.3941 [physics.hist-ph]. 
Beijing Observatory, 1988, General Compilation of Chinese ancient Astronomical Records. Beijing Observatory, Beijing.

Biot E., 1841, Catalogue Général Des Étoiles Filantes Et Des Autres Météores Observés en China. Mémories présentes par divers savants à l'academie royale des sciences. x. p 129 and p 415

Brown P., Wong D.K., Weryk R.J., Wiegert P., 2010, Icarus, 207, 1, p 66

Chasles M. 1841, Catalogue d'aparitions d'étoiles filantes pendant six siècles; de 538 a 1123. Comptes rendus de l'academie des sciences. 12, p 499

Cook D. 1999, JHA. Xxx, p 131.

Dall'Olmo U. 1978, JHA, ix, p 123

Dall'Olmo U., 1980, JHA, xi, p 10

España Sagrada. Teatro geográfico histórico de la Iglesia de España. (51 Volumes, Flores etc. Madrid. 1747-1957)

Fisher, W.J., 1934, Bull. Harvard Coll. Obs, 894, p 15

Fox, K., 1986 in Rickman H. and Langerkvist (eds) Asteroids, comets and meteors, C.-I. Uppsala: University of Uppsala, p 523

Fox, K. ,Williams I.P., Hughes D.W., 1982, MNRAS, 199, p 313

Fox, K. ,Williams I.P., Hughes D.W, 1985, MNRAS, 217, p 407

Fujiwara Y., Hasegawa I. 2001 in Warmbein B. ed. Proceedings of the Meteoroids 2001 Conference. Swedish Institute of Space Physics, Kiruna, Sweden, p 209

Hasegawa.I., 1979, Publ. Astron. Soc. Japan. 31, p 257

Hasegawa.I. , 1992, Cel Mechs, 54, p 129

Hasegawa.I., 1993, In J.Stohl and I.P Williams (Eds.) Meteors and their parent bodies. Astronomical Inst., Slovk Acad. Sci., Bratislava. p 209

Hasegawa.I. , 1996, Q. J.R. Astron. Soc. 37, p 75

Hasegawa I., 1999, In Meteoroids 1998. Astron. Inst., Slovak Acad. Sci., Bratislava, p 177

Ho Peng Yoke, 1962, Vistas in Astronomy, 5, p 127

Hughes D.W., Emerson B., 1982, The Observatory, 102, p 39

Imoto S., Hasegawa I., 1958, Smithsonian Contribution to Astrophysics. 2, p.131

Jenniskens J., 1994, A \& A, 287, p 990

Jenniskens J., 1997, A \& A, 317, p 953

Jenniskens J., 2006, Meteor Showers and their parent comets. Cambridge University Press.

Jenniskens J. et al., 2016, Icarus. 266. 331-354. 2016

Jenniskens, P., Betlem, H., de Lignie, M., Langbroek, M., van Vliet, M, 1997, A\&A, 327, p 1242.

Jopek T.J., Kan̆uchová Z., 2016, Planetary and Space Science (in press)

http://dx.doi.org/10.1016/j.pss.2016.11.003

Kidger M.R., 1993, Q. J.R. Astron. Soc. 34, p 331

Kronk G.W., 2014, Meteor Showers. An annotated catalog. Springer. New York

Mason J.W., 1995, J. Br. Astron. Assoc., 105, 5, p 219

Muratori, RIS: Rerum Italicarum Scriptores ab anno aerae christianae 500 ad 1500. 25 vols Mediolani, 1723-1751

Muratori, RIS 2 : Rerum Italicarum Scriptores ab anno aerae christianae 500 ad 1500. Editio altera. Città di Castello, etc, 1900-

Newton H.A. 1864, The original accounts of the displays in former times of the November starshower. The American Journal of Science and Arts. $2^{\text {nd }}$ Series. 37, p 377

Pankenier D., Zhentao Xu, Yaotiao Jiang, 2008, Archaeoastronomy in East Asia: Historical Observational Records of Comets and Meteor Showers from China, Japan, and Korea. Cambria Press. 
PMH: Portugale Monumenta Historica. (Olisipone: 1856)

Quetelet A. 1841, Catalogue Nouveau des principals aparitions d'étoiles filantes. Memoires de I'Academie Royale des Sciences et Belles-Lettres de Bruxelles. 15, p 21

Rada W.S., Stephenson F.R., 1992 Q. J.R. Astron. Soc. 33, p 5

Toth J, 1999, in Baggaley W. J., Porubcan V. eds, Meteoroids 1998. Astron. Inst. Slovak Acad. Sci., Bratislava, p. 223

Wiegert P., Brown P., 2004, Earth, Moon and Planets. 95, p 81

Williams I.P., Wu Z., 1996, MNRAS. 280, p 1210

Yang H.J., Park, Ch., Park M., 2005, Icarus, 175, p 215

Yau K, Yeomans D., Weismann P., 1994, MNRAS, 266, p 305

Yeomans D. K., Yau K.K. Weismann P.R., 1996, Icarus, 124, p 407

Yrjöla L., Jenniskens J., 1998, A\&A. 330, p 739 